\title{
PENERAPAN MODEL PEMBELAJARAN PROBLEM-BASED LEARNING DENGAN METODE DEBAT TERHADAP KETERAMPILAN BERTANYA MAHASISWA MATA KULIAH ILMU KEALAMAN DASAR UNIVERSITAS MUHAMMADIYAH PALANGKARAYA
}

\section{Application of Problem-Based Learning Model with Debate Method on Asking Skill in Basic Science Subjects at Universitas Muhammadiyah Palangkaraya}

\author{
*Nurul Hikmah Kartini \\ Primary School Teacher Program, Universitas Muhammadiyah Palangkaraya, RTA Milono St. Km.1,5 \\ Palangka Raya, Indonesia \\ *e-mail : nurul.kartini@umpalangkaraya.ac.id
}

\begin{abstract}
ABSTRAK
Penelitian ini menggunakan rancangan eksperimen semu yang bertujuan untuk mengukur keterampilan bertanya mahasiswa melalui penerapan model Problem-Based Learning (PBL) dengan metode Debat, yang secara khusus tujuan penelitian sebagai berikut: 1) mendeskripsikan keterampilan bertanya, dan 2) mendeskripsikan pelaksanaan pembelajaran. Populasi dalam penelitian ini adalah mahasiswa semester III yang mengambil mata kuliah IImu Kealaman Dasar semester ganjil tahun akademik 2017/2018. Sampel penelitian adalah mahasiswa program studi Administrasi Negara yang berjumlah 35 orang sebagai kelas kontrol yang menggunakan model PBL, dan program studi PGSD yang berjumlah 38 orang sebagai kelas pelakuan yang menggunakan model PBL dengan metode debat. Penetapan sampel ditetapkan secara purposive. Data keterampilan bertanya akan dianalisis secara deskriptif setelah ditabulasi dengan kriteria baik sekali, baik, sedang, rendah, rendah sekali. Hasil penelitian menunjukkan bahwa Keterampilan bertanya mahasiswa dengan model PBL dengan menggunakan metode debat mengalami jumlah yang lebih banyak muncul dibandingkan kelas kontrol. Rincian hasilnya adalah dari 10 kriteria pertanyaan, yang dominan muncul adalah kriteria 3 yaitu pertanyaan yang muncul secara logis dari pengamatan-pengamatan yang dibuat dengan angka $25 \%$, kriteria 6 yaitu pertanyaan menganalisis pengamatan-pengamatan dengan angka $25 \%$, dan kriteria 8 yaitu pertanyaan yang mengarah pada prediksi-prediksi yang masuk akal dengan angka $50 \%$.
\end{abstract}

Kata kunci: Problem-Based Learning, Debat, Keterampilan bertanya

\begin{abstract}
This study uses a quasi-experimental design that aims to measure students' questioning skills through the application of Problem-Based Learning (PBL) model with Debate method, which is specifically the purpose of the research as follows: 1) describe the skills of inquiring, and 2) describe the implementation of learning. The population in this study is the third semester students who take Basic Basic Science courses in the odd semester of academic year 2017/2018. The sample of this research is the students of State Administration study program which amounted to 35 people as control class using PBL model, and PGSD study program which amounted to 38 people as a class of actor using PBL model with method of debate. Sample determination is determined purposively. Question skill data will be analyzed descriptively after being tabulated with criteria of excellent, good, medium, low, very low. The results showed that students' questioning skills with the PBL model using the debate method experienced a higher number of emerging than the control class. Details of the results are from 10 criteria of questions, the dominant emerging is criterion 3 is the question that arises logically from the observations made with the number $25 \%$, criterion 6 is the question of analyzing the observations with the number $25 \%$, and criterion 8 is the question leads to reasonable predictions with a $50 \%$.
\end{abstract}

Keywords: Problem-Based Learning, Debate, Asking skill

\section{PENDAHULUAN}

Fungsi Pendidikan Nasional berdasarkan Undang-

Undang Sistem Pendidikan Nasional RI No. 20
Tahun 2003 Pasal 3 disebutkan bahwa

"Pendidikan nasional berfungsi mengembangkan kemampuan dan membentuk watak serta 
peradaban bangsa yang bermartabat dalam rangka mencerdaskan kehidupan bangsa, bertujuan untuk berkembangnya potensi peserta didik agar menjadi manusia yang beriman dan bertakwa kepada Tuhan Yang Maha Esa, berakhlak mulia, sehat, berilmu, cakap, kreatif, mandiri, dan menjadi warga negara yang demokratis serta bertanggung jawab“.

Harapan terhadap pendidikan yang tertuang dalam aturan hukum tersebut menitikberatkan kepada semua aspek pendidikan baik tenaga pengajar maupun peserta didik Peserta didik untuk melaksanakan proses pembelajaran.

Konsep pembelajaran IImu Kealaman Dasar mengutamakan keaktifan Peserta didik membangun pengetahuannya sendiri, membandingkan informasi baru dengan pemahaman yang telah dimiliki, dan menggunakan semua pengetahuan atau pengalaman untuk belajar melalui perbedaan-perbedaan yang ada pada pengetahuan baru dan lama untuk mencapai pemahaman baru. Hal ini menunjukkan adanya perubahan paradigma pendidikan, yaitu perubahan dari paradigma behavioristik menjadi paradigma konstruktivistik. Paradigma konstruktivistik menekankan pada refleksi diri dan pembentukan pengetahuan yang memiliki konstribusi bagi perkembangan keterampilanketerampilan metakognitif.

Kenyataan di lapangan, dalam beberapa materi mahasiswa hanya menghapal konsep dan kurang mampu mengimplementasikan konsep tersebut jika menemui masalah dalam kehidupan nyata yang berhubungan dengan konsep yang dimiliki. Lebih jauh lagi, bahkan mahasiswa kurang mampu menentukan masalah dan merumuskannya, serta membangun sifat keingintahuan melalui pertanyaan masih belum optimal.

Boud dan Felleti (1998) menyatakan bahwa "Problem Based Learning is a way of constructing and teaching course using problem as a stimulus and focus for student activity". H.S. Barrows (1980) menyatakan bahwa PBL adalah sebuah metode pembelajaran yang didasarkan pada prinsip bahwa masalah (problem) dapat digunakan sebagai titik awal untuk mendapatkan atau mengintegrasikan ilmu (knowledge) baru. Dengan demikian, masalah yang ada digunakan sebagai sarana agar anak didik belajar sesuatu.

Titik awal pembelajaran berdasarkan masalah dalam kehidupan nyata yaitu peserta didik dirangsang untuk mempelajari masalah berdasarkan pengetahuan dan pengalaman yang telah mereka punyai sebelumnya (prior knowledge) sehingga dari prior knowledge ini akan terbentuk pengetahuan dan pengalaman baru. Diskusi dengan menggunakan kelompok kecil merupakan poin utama dalam penerapan PBL. Tidak selamanya proses belajar dengan metode PBL berjalan dengan lancar. Ada beberapa hambatan yang muncul, paling sering terjadi adalah kurang terbiasanya peserta didik dan pengajar dengan metode ini. Peserta didik dan pengajar masih terbawa kebiasaan metode konvensional, pemberian materi terjadi secara satu arah. Faktor penghambat lain adalah kurangnya waktu. Proses PBL terkadang membutuhkan waktu yang lebih banyak. Peserta didik terkadang memerlukan waktu untuk menghadapi persoalan yang diberikan. Sementara, waktu pelaksanaan PBL harus disesuaikan dengan beban kurikulum. Penggunaan pendekatan PBL ini, peserta didik akan bekerja secara kooperatif dalam kumpulan 
untuk menyelesaikan masalah sebenarnya dan yang paling penting membina kemahiran untuk menjadi peserta didik yang belajar secara sendiri (Hamizer dkk, 2003).

PBL berbeda dengan metode konvensional. Metode konvensional berupa ceramah yang memusatkan perhatian peserta didik sepenuhnya kepada guru sehingga yang aktif di sini hanya guru, sedangkan peserta didik hanya tunduk mendengarkan penjelasan yang dipaparkan. Partisipasi peserta didik rendah karena hanya diberi kebebasan untuk bertanya mengenai materi yang telah dijelaskan oleh guru sehingga metode konvensional masih kurang menggugah daya pemikiran peserta didik. Sedangkan, metode PBL adalah metode pembelajaran yang berbasis kepada partisipasi para peserta didik. Pada jam pertama pembelajaran, metode yang diterapkan adalah diskusi. Guru memberikan pertanyaan kepada peserta didik yang ditunjuk secara acak. Pertanyaan yang diajukan bersifat menggali pendapat dan mengembangkan kemampuan analisis peserta didik. Kemudian, pada satu jam terakhir, guru memberikan rangkuman dan inti dari diskusi pada hari itu disertai dengan inti dari konteks materi dihubungkan dengan implementasi di lapangan.

PBL memiliki sintaks khusus yang membedakannya dengan model-model pembelajaran yang lain. Sintaks PBL terdiri dari lima tahap utama seperti ditunjukkan pada tabel berikut:

Tabel 1. Sintaks PBL

\begin{tabular}{llr}
\hline \multicolumn{1}{c}{ Tahap } & \multicolumn{3}{c}{ Tingkah laku guru } \\
\hline Tahap-1 & Guru menjelaskan tujuan \\
Orientasi Peserta & pembelajaran, menjelaskan logistik \\
didik kepada & yang dibutuhkan, mengajukan \\
masalah & fenomena atau demonstrasi atau cerita \\
& untuk memunculkan masalah, \\
& memotivasi Peserta didik untuk terlibat \\
\hline
\end{tabular}

dalam pemecahan masalah yang dipilihnya.

\begin{tabular}{|c|c|}
\hline $\begin{array}{l}\text { Tahap-2 } \\
\text { Mengorganisasi } \\
\text { Peserta didik } \\
\text { untuk belajar. }\end{array}$ & $\begin{array}{l}\text { Guru menjelaskan, Peserta didik } \\
\text { mendefinisikan dan mengorganisasikan } \\
\text { tugas belajar yang berhubungan } \\
\text { dengan masalah tersebut. }\end{array}$ \\
\hline $\begin{array}{l}\text { Tahap-3 } \\
\text { Membimbing } \\
\text { penyelidikan } \\
\text { individual } \\
\text { maupun } \\
\text { kelompok }\end{array}$ & $\begin{array}{l}\text { Guru mendorong Peserta didik untuk } \\
\text { mengumpulkan informasi yang sesuai, } \\
\text { melaksanakan eksperimen untuk } \\
\text { mendapat penjelasan dan } \\
\text { memecahkan masalah }\end{array}$ \\
\hline $\begin{array}{l}\text { Tahap-4 } \\
\text { Mengembangkan } \\
\text { dan menyajikan } \\
\text { hasil karya }\end{array}$ & $\begin{array}{l}\text { Guru membantu Peserta didik dalam } \\
\text { merencanakan dan menyiapkan karya } \\
\text { yang sesuai seperti laporan, video, } \\
\text { beserta model dan membantu mereka } \\
\text { untuk berbagi tugas dengan temannya }\end{array}$ \\
\hline $\begin{array}{l}\text { Tahap-5 } \\
\text { Menganalisis dan } \\
\text { mengevaluasi } \\
\text { proses } \\
\text { pemecahan } \\
\text { masalah }\end{array}$ & $\begin{array}{l}\text { Guru membantu Peserta didik untuk } \\
\text { melakukan refleksi atau evaluasi } \\
\text { terhadap penyelidikan mereka dan } \\
\text { proses-proses yang mereka gunakan. }\end{array}$ \\
\hline & \\
\hline
\end{tabular}

Menurut Zaini, dkk (2008: 38), debat bisa menjadi satu cara berharga yang dapat mendorong pemikiran dan perenungan terutama kalau peserta didik diharapkan mempertahankan pendapat yang bertentangan dengan keyakinannya sendiri. Ini merupakan strategi yang secara aktif melibatkan setiap peserta didik di dalam kelas bukan hanya para pelaku debatnya saja.

Langkah-langkah metode debat seperti yang diungkapkan Hisyam, dkk (2008:38-39) sebagai berikut:

1. Kembangkan sebuah pernyataan yang kontroversial yang berkaitan dengan materi pelajaran/perkuliahan

2. Bagi kelas kedalam dua tim. Mintalah satu kelompok yang "pro" dan kelompok yang "kontra".

3. Berikutnya, buat dua sampai empat sub kelompok dalam masing-masing kelompok debat. Setiap sub kelompok diminta mengembangkan argumen yang mendukung 
masing-masing posisi. Diakhir diskusi, setiap sub kelompok memilih seorang juru bicara.

4. Siapkan dua sampai empat kursi untuk para juru bicara. Mulailah debat dengan para juru bicara mempresentasikan pandangan mereka. Proses ini disebut argumen pembuka.

5. Setelah mendengarkan argumen pembuka, setiap sub kelompok mempersiapkan argumen mengkaunter argumen pembuka dari kelompok lawan. Setiap sub kelompok memilih juru bicara yang berbeda.

6. Lanjutkan kembali debat. Juru bicara yang saling berhadapan diminta untuk memberikan kaunter argumen. Ketika debat berlangsung, peserta yang lain didorong untuk memberikan catatan yang berisi usulan argumen atau bantahan. Minta mereka untuk bersorak atau bertepuk tangan untuk masing-masing argumen dari para wakil kelompok.

7. Pada saat yang tepat akhiri debat. Tidak perlu menentukan kelompok mana yang menang, buatlah kelas melingkar. Pastikan bahwa kelas terintegrasi dengan meminta mereka duduk berdampingan dengan mereka yang berada di kelompok lawan. Diskusikan apa yang peserta didik untuk mengidentifikasi argumen yang paling baik menurut mereka.

Menurut Tarigan (Nurdin, 2016: 2), metode debat aktif merupakan salah satu metode yang diciptakan oleh Malvin L.Sibermen dalam pembelajaran aktif (Active Learning). Metode ini digunakan untuk menstimulasi diskusi kelas. Melalui metode debat aktif peserta didik didorong untuk mengemukakan pendapatnya melalui suatu perdebatan antar kelompok diskusi yang disatukan dalam sebuah diskusi kelas. Debat merupakan suatu argumen untuk menentukan baik tidaknya suatu usul tertentu yang didukung oleh suatu pihak yang disebut pendukung atau afirmatif, dan ditolak, disangkal oleh pihak lain yang disebut penyangkal atau negatif.

Sementara menurut Kamdhi (Nurdin, 2016:2) debat adalah suatu pembahasan atau pertukaran pendapat mengenai suatu pokok masalah dimana masing-masing peserta memberikan alasan untuk mempertahankan pendapatnya.

Fredrizzi dan Ellis (2008: 30) menyatakan bahwa " Debate is defined as oral confrontation between two individuals, teams, or groups to argue reasons for and against a set position". Debat pada hakekatnya adalah saling adu argumentasi antar pribadi atau antar kelompok manusia, dengan tujuan mencapai kemenangan satu pihak. Debat adalah kegiatan adu argumentasi antara dua pihak atau lebih, baik secara perorangan maupun kelompok, dalam mendiskusikan dan memutuskan masalah dan perbedaan. Debat terbagi menjadi dua macam yaitu debat informal dan formal.

Keterampilan bertanya merupakan keterampilan yang bersifat mendasar yang dipersyaratkan bagi penguasaan keterampilan berikutnya. Untuk dapat menguasai keterampilan memberi penguatan kita dituntut sudah menguasai keterampilan bertanya dengan kata lain kita tidak mungkin menguasai keterampilan memberi penguatan apabila kita belum menguasai keterampilan bertanya. Bertanya memegang fungsi yang penting dalam proses belajar mengajar. Prestasi belajar siswa akan meningkat jika dalam proses belajar mengajar dilibatkan bentuk-bentuk pertanyaan yang bertaraf tingkatan yang lebih tinggi.

Brown dan Wragg (1993) mengemukakan mengapa orang-orang menanyakan pertanyaan. Penerapan pertanyaan dikeluarkan ketika kita 
ingin mengetahui sesuatu. Aspek kognitif, afektif dan sosial dapat dibedakan ketika pertanyaan diajukan, berkaitan dengan pengetahuan, perasaan dan hubungan. Sehingga berlanjut ke tahap mencari informasi ataupun solusi dari permasalahan. Pemahaman terhadap hal yang berbeda dalam kondisi tertentu kaitannya dengan interaksi sosial menyebabkan kita dapat memahami orang lain.

Tabel 2. Aspek- Aspek Keterampilan Bertanya

\begin{tabular}{|c|c|}
\hline No & Kriteria Pertanyaan \\
\hline 1. & $\begin{array}{l}\text { Pertanyaan-pertanyaan penuh pemikiran dan relevan } \\
\text { diajukan }\end{array}$ \\
\hline 2. & Pertanyaan-pertanyaan dirumuskan dengan baik \\
\hline 3. & $\begin{array}{l}\text { Pertanyaan-pertanyaan muncul secara logis dari } \\
\text { pengamatan-pengamatan yang dibuat }\end{array}$ \\
\hline 4. & $\begin{array}{l}\text { Pertanyaan-pertanyaan merupakan deskripsi dari } \\
\text { pengamatan }\end{array}$ \\
\hline 5. & $\begin{array}{ll}\text { Pertanyaan-pertanyaan } & \text { menginterpretasikan } \\
\text { pengamatan-pengamatan } & \end{array}$ \\
\hline 6. & $\begin{array}{l}\text { Pertanyaan-pertanyaan menganalisis pengamatan- } \\
\text { pengamatan }\end{array}$ \\
\hline 7. & $\begin{array}{l}\text { Pertanyaan-pertanyaan mengarah pada pengamatan- } \\
\text { pengamatan }\end{array}$ \\
\hline 8. & $\begin{array}{l}\text { Pertanyaan-pertanyaan mengarah pada prediksi- } \\
\text { prediksi yang masuk akal }\end{array}$ \\
\hline 9. & Suatu pertanyaan dipilih untuk penyelidikan \\
\hline 10. & $\begin{array}{l}\text { Suatu justifikasi penuh pemikiran diberikan untuk apa } \\
\text { pertanyaan-pertanyaan tersebut dipilih guna } \\
\text { penelitian lebih lanjut }\end{array}$ \\
\hline
\end{tabular}

Berdasarkan observasi di Universitas Muhammadiyah Palangkaraya menunjukkan sebagian besar mahasiswa hanya terpusat pada pemberian materi saja dan belum memperkaya wawasan pengetahuan mereka dengan kondisi kekinian yang terjadi di lingkungan sekitarnya.

Mempelajari hal-hal yang terkait IImu Kealaman Dasar pastinya tidak jauh dari disiplin ilmu fisika, biologi, dan kimia yang berkaitan dengan kehidupan sehari-hari. Kondisi alam di Kalimantan Tengah terutama Sumber Daya Alamnya sangat menarik untuk dipelajari lebih mendalam. Berdasarkan hal tersebut, maka peneliti tertarik untuk melaksanakan pembelajaran dengan menggunakan dua buah model pembelajaran yang inovatif yaitu Problem Based Learning (PBL) dan Debat. Dua model ini memiliki sintaks atau langkah-langkah pembelajaran yang serupa, namun dengan karakteristiknya masing-masing yang menjadi keunggulan dari model tersebut. Materi pada mata kuliah IImu Kealaman Dasar yang sesuai dengan model ini adalah materi tentang sumber daya alam yang dipelajari pada pertemuan ketujuh dan delapan. Dengan mengangkat topik/tema kontroversial yang relevan dengan kondisi kealaman Kalimantan Tengah sekarang ini, peneliti berharap proses pembelajaran bisa berjalan dengan interaktif dengan hasil belajar seperti yang diharapkan.

Berdasarkan analisa terhadap permasalahan tersebut, maka peneliti tertarik untuk mengetahui sejauh mana keefektifan penggunaan model PBL dan Debat ini terhadap keterampilan bertanya mahasiswa pada mata kuliah IImu Kealaman Dasar di Universitas Muhammadiyah Palangkaraya.

\section{METODOLOGI}

Metode penelitian ini adalah penelitian kualitatif berupa studi kasus yang bertujuan untuk mengukur keterampilan bertanya mahasiswa melalui penerapan model PBL dengan metode Debat. Subjek dalam penelitian ini adalah mahasiswa semester III yang mengambil mata kuliah IImu Kealaman Dasar semester ganjil tahun akademik 2017/2018 di program studi PGSD yang berjumlah 38 orang. Data keterampilan bertanya akan dianalisis secara deskriptif kualitatif setelah melalui tahapan tabulasi data dengan kriteria persentase. Waktu penelitian dari Bulan Oktober 2017 sampai dengan Januari 2018. Lokasi 
Penelitian di Kampus I UM Palangkaraya, JI. RTA Milono km 1,5 Palangka Raya. Data diambil dengan menggunakan lembar observasi. Data yang terkumpul kemudian dianalisis secara deskriptif kualitatif. Untuk mengolah data hasil keterampilan bertanya melalui lembar observasi.

Penelitian ini dilakukan selama 3 (tiga) bulan dimulai pada bulan Oktober - Desember 2017. Lokasi Penelitian dilaksanakan di Universitas Muhammadiyah Palangkaraya.

\section{HASIL DAN PEMBAHASAN}

Data kualitatif penelitian meliputi keterampilan bertanya, dan beberapa instrumen dalam kegiatan pembelajaran.

\section{Keterampilan bertanya}

Frekuensi hasil pengamatan keterampilan bertanya seperti pada Tabel 3 .

Tabel 3. Frekuensi Hasil Pengamatan Keterampilan Bertanya

\begin{tabular}{|c|c|c|}
\hline No & Aspek keterampilan bertanya & Frekuensi \\
\hline 1 & $\begin{array}{l}\text { Pertanyaan yang diajukan relevan } \\
\text { dengan permasalahan }\end{array}$ & 14 \\
\hline 2 & $\begin{array}{l}\text { Pertanyaan-pertanyaan dirumuskan } \\
\text { dengan baik }\end{array}$ & 0 \\
\hline 3 & $\begin{array}{l}\text { Pertanyaan-pertanyaan muncul secara } \\
\text { logis dari pengamatan-pengamatan } \\
\text { yang dibuat }\end{array}$ & 10 \\
\hline 4 & $\begin{array}{ll}\text { Pertanyaan-pertanyaan } & \text { merupakan } \\
\text { deskripsi dari pengamatan } & \end{array}$ & 0 \\
\hline 5 & $\begin{array}{l}\text { Pertanyaan-pertanyaan } \\
\text { menginterpretasikan pengamatan }\end{array}$ & 0 \\
\hline 6 & $\begin{array}{l}\text { Pertanyaan-pertanyaan menganalisis } \\
\text { pengamatan }\end{array}$ & 12 \\
\hline 7 & $\begin{array}{l}\text { Pertanyaan-pertanyaan mengarah pada } \\
\text { pengamatan }\end{array}$ & 10 \\
\hline 8 & $\begin{array}{l}\text { Pertanyaan-pertanyaan mengarah pada } \\
\text { prediksi yang masuk akal }\end{array}$ & 6 \\
\hline 9 & $\begin{array}{l}\text { Suatu pertanyaan dipilih untuk } \\
\text { penyelidikan }\end{array}$ & 6 \\
\hline 10 & $\begin{array}{l}\text { Suatu justifikasi penuh pemikiran } \\
\text { diberikan untuk apa pertanyaan- } \\
\text { pertanyaan tersebut dipilih guna } \\
\text { penelitian lebih lanjut }\end{array}$ & 0 \\
\hline \multicolumn{2}{|c|}{ Jumlah } & 52 \\
\hline
\end{tabular}

Berdasarkan Tabel 3. aspek keterampilan bertanya banyak muncul pada kriteria 1, 3, 6, 7, 8, dan 9 yang menggunakan model PBL dengan Metode Debat. Pertanyaan yang muncul saat pembelajaran muncul pada sesi kedua debat yang secara spesifik memang diperuntukkan untuk pertanyaan kepada lawan. Jadi setelah sesi pertama berupa penyampaian argumen, pihak pro maupun yang kontra akan memberikan pertanyaan kepada kelompok lawan mengacu dari pernyataan pembuka sebelumnya. Sesi selanjutnya yang juga muncul banyak pertanyaan adalah pada sesi keempat yaitu debat terbuka. Mengacu pada konsep pertanyaan secara umum: apa, dimana, mengapa, siapa, kapan, dan bagaimana dikemukakan oleh masing-masing kelompok mengacu pada materi yang diperdebatkan yaitu keberadaan penambang ilegal di Kalimantan Tengah.

\section{Pelaksanaan Pembelajaran}

Penilaian terhadap pembelajaran terdiri atas 1 ) keterlaksanaan pembelajaran, dan 2) penilaian afektif.

1. Frekuensi hasil pengamatan keterlaksanaan sintak pembelajaran seperti Tabel 4 . berikut:

Tabel 4. Frekuensi hasil pengamatan keterlaksanaan sintak pembelajaran

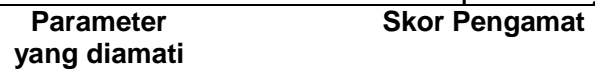

\begin{tabular}{lcccc} 
& 1 & 2 & Rata-rata & Kategori \\
\hline Pembukaan & 80 & 80 & 80 & Baik \\
\hline $\begin{array}{l}\text { Kegiatan Inti } \\
\text { (5 langkah) }\end{array}$ & 78 & 76 & 77 & Baik \\
\hline Penutup & 80 & 78 & 79 & Baik \\
\hline
\end{tabular}

Berdasarkan Tabel 4. keterlaksanaan sintak pembelajaran semuanya pada kategori baik. Berdasarkan lembar observasi yang dilakukan oleh 2 (dua) orang observer yaitu satu orang dosen dan satu orang mahasiswa yang sedang menempuh tugas akhir. Rerata nilai hasil pengamatan pada kegiatan pembukaan, 
kegiatan inti dan kegiatan penutup ada pada kategori baik, artinya dosen yang melaksanakan pembelajaran sudah sesuai dengan rencana pembelajaran.

2. Frekuensi pengamatan terhadap Afektif Mahasiswa disajikan pada Tabel 5.

Tabel 5. Frekuensi hasil afektif

\begin{tabular}{|c|c|c|c|c|}
\hline \multirow{2}{*}{$\begin{array}{c}\text { Parameter } \\
\text { yang diamati }\end{array}$} & \multicolumn{4}{|c|}{ Skor Pengamat } \\
\hline & $\sum_{\text {mahasiswa }}^{\Sigma}$ & Eskor & Rata-rata & Kategori \\
\hline $\begin{array}{l}\text { Menyumbang } \\
\text { ide / pendapat }\end{array}$ & 38 & 2833 & 75 & Baik \\
\hline $\begin{array}{l}\text { Menjadi } \\
\text { pendengar } \\
\text { yang baik }\end{array}$ & 38 & 2990 & 79 & Baik \\
\hline Komunikasi & 38 & 2998 & 79 & Baik \\
\hline $\begin{array}{l}\text { Tanggung } \\
\text { jawab }\end{array}$ & 38 & 2820 & 74 & Baik \\
\hline Bekerja sama & 38 & 2934 & 77 & Baik \\
\hline $\begin{array}{l}\text { Terbuka dan } \\
\text { menghargai } \\
\text { pendapat } \\
\text { teman }\end{array}$ & 38 & 2853 & 75 & Baik \\
\hline
\end{tabular}

Berdasarkan Tabel 5. pengamatan terhadap afektif terlihat bahwa semuanya memiliki kategori baik.

\section{KESIMPULAN}

Keterampilan Bertanya yang muncul adalah dari 10 kriteria pertanyaan, sebagian besar adalah kriteria 1, 3, 6, 7, 8, dan 9 yaitu: a). Kriteria 1, Pertanyaan yang diajukan relevan dengan permasalahan dengan persentase sebanyak 26,92\%; b) Kriteria 3, pertanyaan yang muncul secara logis dari pengamatan-pengamatan yang dibuat dengan persentase sebanyak $19,23 \%$; c) kriteria 6 , pertanyaan menganalisis pengamatanpengamatan dengan persentase sebanyak 23,08\%; d) Kriteria 7, Pertanyaan-pertanyaan mengarah pada pengamatan dengan persentase sebanyak $19,23 \%$; e) kriteria 8 , pertanyaan yang mengarah pada prediksi-prediksi yang masuk akal dengan persentase sebanyak $11,54 \%$; f) kriteria 9 , pertanyaan dipilih untuk penyelidikan dengan persentase sebanyak $11,54 \%$. Penilaian terhadap pembelajaran menyimpulkan pada kategori baik, dengan rincian: 1) kegiatan pembukaan sebesar $80 \%$; 2) kegiatan inti sebesar $77 \%$, dan 3) kegiatan penutup adalah $79 \%$. Keterampilan Afektif pada kategori baik dengan rincian: 1) menyumbang ide/pendapat sebesar 75\%; 2) menjadi pendengar yang baik sebesar $79 \%$; 3) komunikasi sebesar $79 \%$; 4) tanggung jawab sebesar $74 \%$; 5) bekerja sama sebesar $77 \%$; dan 6) terbuka, menghargai pendapat teman sebesar $75 \%$. Keterampilan bertanya yang diharapkan timbul dengan pembelajaran debat memang sudah terpenuhi, namun tidak semua aspek pertanyaan terpenuhi yang mana hal ini menunjukkan dengan keterbatasan waktu dalam forum debat menyebabkan pertanyaan yang dikeluarkan belum terlalu mendalam menggali pengetahuan tentang materi yang diangkat. Oleh karena itu perlu dilakukan pembiasaan model debat dalam pembelajaran sehingga manajemen waktu yang ada dapat dimanfaatkan dengan maksimal.

\section{DAFTAR PUSTAKA}

Badan Standar Nasional Pendidikan. 2006. Undang-Undang Nomor 20 Tahun 2003 tentang Sistem Pendidikan Nasional, Jakarta: Badan Standar Nasional Pendidikan

Emzir. Metodologi Penelitian Pendidikan, Jakarta: PT. Rajagrafindo Persada

Furqan, A. 1990. Pengantar Penelitian dalam Pendidikan, Surabaya: Usaha Nasional Surabaya.

Hibbard, M. 2006. Performance Assessment. New York: Glencoe McGraw-Hill 
Martiyono. 2012. Perencanaan Pembelajaran. Yogyakarta: Aswaja Pressindo

Nurdin, M. 2016. Penerapan Metode Debat Aktif untuk Meningkatkan Kemampuan Berdiskusi Mahasiswa dalam Pembelajaran Konsep Dasar PKn di PGSD UPP Bone FIP UNM. Jurnal Publikasi Pendidikan Volume $\mathrm{VI}$, Nomor 1, 1-7

Sanjaya, W. 2011. Strategi Pembelajaran Berorientasi Standar Proses Pendidikan. Jakarta: Kencana Prenada Media

Suwanda. 2011. Desain Eksperimen. Bandung: Alfabeta

Tim Penyusun. 2008. Strategi Pembelajaran dan Pemilihannya. Dirjen PMPTK: Tidak diterbitkan

Zaini, H., Munthe, B., \& Aryani, S.A. 2008. Strategi Pembelajaran Aktif. Yogyakarta: Pustaka Insan Madani 